\title{
Using classroom communication systems to support interaction and discussion in large class settings
}

\author{
James T. Boyle and David J. Nicol \\ University of Strathclyde \\ email: dj.nicol@strath.ac.uk
}

Teaching methods that promote interaction and discussion are known to benefit learning. However, large class sizes make it difficult to implement these methods. Research from the United States has shown that an electronic classroom communication system (CCS) can be used to support active discussion in large lecture classes. This investigation extends that research and it evaluates students' and teachers' experiences of CCS technology in the context of two different modes of discussion - peer-group and classwide discussion. With CCS technology, students' answers to multiple-choice concept tests are collated in real time with the class results fed back as a histogram. This information serves as the trigger for each mode of discussion. This paper explores the unique contribution of CCS technology, the relative strengths of peer-and class-wide discussion and some practical implementation issues.

\section{Introduction}

There is now a considerable body of research that shows that deep and lasting learning is fostered when students actively engage with the concepts they are learning and construct their own understanding of them (for example, DeCorte, 1996; Hake, 1998; Glaser, 1990; Palinscar, 1998). Discussion, debate, questioning and explaining are some of the activities that have been shown to support active learning and the construction of meaning in the classroom (for example, Laurillard, 1993; Cohen, 1994; Matthews, 1996; Springer, Stanne and Donovon, 1999). Yet, in most universities, lecture classes usually carry large enrolments and this militates against active engagement and discussion. Moreover, class sizes are unlikely to diminish given government policies on wider access in the UK and elsewhere. In response to this dilemma a growing number of teachers have, in recent years, been searching for ways of making large classes more interactive (Bligh, 2000; MacGregor, Cooper, Smith and 
Robinson, 2000; Edwards, Smith and Webb, 2001). One approach that has proved successful in the United States is to use new technology to manage discussions in large lecture classes.

The Physics Education Research Group (PERG) at the University of Massachusetts (Dufresne, Gerace, Leonard, Mestre and Wenk, 1996) and investigators from the Galileo Project Group at Harvard (Mazur, 1997; Crouch and Mazur, 2001) have been researching ways of improving conceptual learning in the sciences. The basic approach adopted by these researchers is to break up lecture inputs with concept questions (multiple choice tests) and in-class discussions using a classroom communication system (CCS). A CCS is a software/hardware configuration that makes it possible for students to signal their responses to the concept questions using handset transmitters and for these responses to be collated in real time and publicly displayed as a histogram. It is this feedback that is used to trigger and sequence in-class discussions.

Research has shown that these technology-supported discussion methods lead to improvements in students' conceptual reasoning and examination performance (Crouch and Mazur, 2001; Defresne et al., 1996). These findings are interpreted from a social constructivist perspective (Palinscar, 1998). The argument is that in-class discussion forces students to explain, analyse and defend their answers to concept questions in the face of questioning by others with different perspectives. This results in more robust and elaborate mental constructions of concepts than would occur in more traditional lecture classrooms (see Nicol and Boyle, 2003, for a more fine-grained analysis of these processes).

This paper describes an initiative in an engineering department in a large university where classroom technology was used to support in-class discussion with large numbers of students. It begins with an explanation of why the department decided to change its teaching methods.

\section{Concerns about teaching and learning}

In 1998 the 'New Approaches to Teaching and Learning in Engineering' (NATALIE) initiative was launched at the University of Strathclyde. The aim was to revitalize teaching and learning in the undergraduate degree programme of the Department of Mechanical Engineering. Three areas of concern led to this initiative. First, lecturers had noticed that most first-year students had difficulty acquiring a deep understanding of certain core concepts. As one lecturer put it 'even the brightest students make inexplicable blunders in the application of these concepts'. This is backed up by research in the sciences which has documented the existence of such 'misconceptions' or 'alternative conceptions' (McDermott, 1984; Brumby, 1984; Halloun and Hestenes, 1985; West and Pines, 1985). They usually occur when the concept conflicts with intuitive beliefs and/or when the concept is highly complex, involving multiple, and often interacting, components.

A second concern was the increasing numbers in lecture classes which limited the potential for interaction and discussion. Lecturers complained that because the flow of information was mainly one-way it was difficult to identify when students were experiencing difficulties. A third area of concern was the motivation of the students. Some lecturers argued that new technology and the information rich society had undermined the value of lectures. Nowadays, students preferred to concentrate for short intense periods on a task or to multitask rather than to concentrate for long periods of time in lectures. 
These three concerns - weak conceptual understanding, insufficient interaction and discussion and low levels of motivation - led staff in the department to search for new ways to teach mechanical engineering.

\section{Addressing the concerns using technology-supported discussion}

\section{Realigning teaching and learning}

Two years of preparation preceded the implementation of the NATALIE initiative. During that time staff from the Department of Mechanical Engineering researched how engineering was taught in a range of institutions in the United States. The model of teaching and learning that was subsequently adopted centred on the idea of 'interactive engagement' (Hake, 1998) which emphasizes learner activity and dialogue. Drawing on the work of both Mazur (1997) and Dufresne et al. (1996), two discussion sequences were integrated into the mechanical engineering lecture classes - peer instruction and class-wide discussion (see Table 1).

Peer instruction: Mazur sequence

I. Concept question posed

2. Individual thinking: students given time to think individually (1-2 min)

3. Students provide individual responses

4. Students receive feedback - poll of responses presented as histogram display

5. Peer discussion: students instructed to convince their neighbours that they have the right answer.

6. Retesting of same concept

7. Students provide individual responses (revised answer)

8. Students receive feedback - poll of responses presented as histogram display

9. Lecturer summarizes and explains 'correct' response
Class-wide discussion: Dufresne sequence

I. Concept question posed

2. Peer discussion: small groups discuss the concept question (3-5 min)

3. Students provide individual responses.

4. Students receive feedback - poll of responses presented as histogram display.

5. Class-wide discussion: students explain their answers and listen to the explanations of others (facilitated by tutor)

6. Lecturer summarizes and explains 'correct' response

Table 1: The sequence of activities for peer instruction and class-wide discussion

Table 1 shows the differences in the discussion methods used within these two sequences. Mazur only uses peer discussion whereas Dufresne uses both peer discussion and classwide discussion. During class-wide discussion, the lecturer facilitates discussion by asking students from different groups to explain to the class the reasoning behind their answer.

As well as addressing the three concerns highlighted above, this study was also designed to add to the research literature on technology-supported discussion. In previously published research, the different discussion methods used by Crouch and Mazur (2001) and Defresne et al. (1996) have been shown to produce learning gains but they have never been directly compared. This study examines the relative merits of peer and class-wide discussion from the perspectives of students and teachers. In addition, little is known about how students experience learning in the 'wired classroom' or about how teachers adapt to these discussion methods and the associated technology. This study also provides some new insights into these processes. 


\section{Description of the Engineering Mechanics class}

In this paper we report on the implementation in 2000-1 of these discussion methods in an Engineering Mechanics class, a two-credit first-year class run over two twelve-week semesters consisting of two two-hour sessions per week. Students were organized into groups of four. They sat in these 'peer groups' throughout the year. The first five weeks of the class comprise an overview of the teaching methodologies to be used and a review of school material. The review allows the Personal Response System (PRS) to be introduced with subject material that is already familiar. New topics are then introduced in two-week sequences. Two lecturers facilitated these interactive sessions. The intake in 2000-1 consisted of 117 students.

The classroom technology used to support these discussion methods was a PRS marketed by Varitronics. PRS comprises a computer and a data projector used to present the concept tests, a set of handsets that allow students to signal their responses to these tests and wallmounted sensors (receivers). The PRS software allows class responses to be collated almost instantaneously and displayed as a histogram or bar chart (for a more detailed description, see Comlekci, Boyle, King, Dempster, Lee, Hamilton and Wheel, 1999).

\section{Example concept tests}

Figures 1 and 2 show two concept tests that are used to initiate discussion on the notion of a contact force. Contact force results from Newton's Third Law of Motion (to every action there is an equal and opposite reaction). When introduced to this concept most students can be led to the common-sense understanding that when standing your weight is pressing down on the floor, so the floor must be pushing back with the same force. The force that pushes back up is the contact force. The first question (Figure 1) is intended to remind the students of their school studies. They normally correctly identify that the contact force is equal to the weight of the crate. However, when asked the second question the majority of students choose Option No.2 - that the contact force remains the same as the weight. The in-class discussion that follows would normally involve students exploring the idea that the contact force must be greater than the person's weight if the lift is accelerating (that is there is an unbalanced force to cause motion). They may also discuss the importance of using force diagrams (rather than common sense), to analyse motion problems.

\section{Evaluation methodology}

The evaluation explored the perceptions and experiences of students and lecturers in the interactive classroom. The main objectives were (1) to ascertain whether these technologysupported teaching methods would help address the three concerns raised by academic staff - weak conceptual understanding, insufficient interaction and discussion in class, and low student motivation and (2) to compare the two different discussion methods (peer and class-wide discussion).

\section{Evaluation methods: students}

Three evaluation methods were used with students. First, discussions were held with five focus groups of six students. This gave a sample size of 25 per cent of class enrolment. Each group met twice - once while 'class-wide discussion' was being used (Week 7) and once while peer instruction (Week 10) was being used. The second author (DJN) and two 
Consider the picture below that shows a crate sitting on the floor.

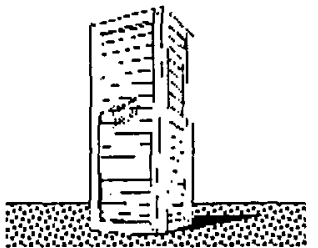

The contact force between the crate and the floor is:

1. Less than

2. Equal to

3. More than

The weight of the crate?
Consider a person standing in an elevator that is accelerating upward. The upward normal force $N$ exerted by the elevator floor on the person is:
1. Larger than
2. Identical to
3. Smaller than

The weight $W$ of the person?

Figures I and 2: Examples of concept tests

other researchers conducted the focus group meetings which were recorded. The first author (JTB) lectured in the class.

The second method was a survey that comprised thirty-six statements. The statements were derived from the focus group data. Issues raised in the focus groups were analysed, interpreted and categorized independeritly by the research team from the recordings. Once agreed, the issues were then re-formulated into single-sentence statements and linked to a five-point Likert scale (see Table 2). The range descriptors were from 'strongly agree' to 'strongly disagree'. While most statements were phrased in the positive sense some were phrased in the negative to discourage rote responses. Five statements also asked students to provide a short reason for their answer. The survey was administered in class at the end of the semester. Responses were anonymous. Only a subset of the survey responses is reported here. Other data are reported in Nicol and Boyle (2003).

The third evaluation method involved the use of a critical incident questionnaire. This was adapted from Brookfield (1995) and comprised a single sheet of A4 with five questions and space for comments. This was distributed to students in Week 5 when both discussion sequences were in use. A typical question was: At what moment in the class did you feel most engaged with what was happening? Why? The intention of this evaluation was to find out about students' immediate experiences in an interactive class.

\section{Evaluation methods: staff}

A focus-group discussion was held with a group of six teaching staff at the end of the academic year about their experiences in preparing materials for, and teaching in, PRSsupported classes. This group included the two lecturers who taught Engineering 
Mechanics, four lecturers who taught other classes within the same department and one lecturer from another department (mathematics).

\section{Results: experiences of students}

In this section we report on students' experiences of learning in the interactive classroom. The results are organized around three headings related to the three concerns that led to the NATALIE initiative.

The students' results comprise both qualitative and quantitative data. The quotes in the text below present a qualitative account of students' experiences. These are drawn from the focus-group discussions and from the written responses to the survey statements. These quotes are linked in the text to the quantitative data from the survey. Each set of data complements the other. The survey data has been organized into three tables (Tables 2, 3 and 4 ) and referenced to the three headings (concerns). When referring to these Tables in the text that follows [T2:S1], for example, would refer to Table 2, survey statement 1 .

\section{Conceptual understanding}

In the focus groups and survey the majority of students reported that in comparison with traditional lecture classes, the teaching methods used in the Engineering Mechanics class were more effective in helping them acquire an understanding of fundamental engineering concepts [T2:S1]. They also reported in the focus groups that the 'PRS methods' (their terminology) helped raise their awareness about which concepts were most appropriate to solve particular classes of engineering problems. This was confirmed in the survey [T2:S2].

\begin{tabular}{lcc}
\hline Number Survey statement & $\begin{array}{c}\text { Students } \\
\text { agree } \\
(\%)\end{array}$ & $\begin{array}{c}\text { Students } \\
\text { diasagree } \\
(\%)\end{array}$ \\
\hline
\end{tabular}

I. Using the PRS helps me develop a better understanding of the subject matter when compared with traditional lecture-based classes. $\quad 74 \quad 4$

2. Using the PRS helps me to understand the concepts behind problems. $75 \quad 6$

3. I am more actively involved during PRS classes than during traditional classes. $95 \quad$ ।

4. I have to think more in PRS classes than in traditional lecture classes. $91 \quad 0$

5. I study less outside PRS classes than for traditional classes. $\quad 24 \quad 24$

6. I remember less after a PRS class than after other classes. $\quad 12 \quad 63$

Note: Figures are derived from responses to a 5-point Likert scale ( $1-5$ with $1=$ strongly agree and $5=$ strongly disagree). Responses 1 and 2 have been combined to represent the percentage of students 'agreeing' with each statement and similarly responses 4 and 5 represent the percentage 'disagreeing'.

The ordering of statements in the table follows the text and was not the order of presentation to students.

Table 2: Student responses to end of semester survey

A number of reasons were given by students to account for their enhanced conceptual understanding. First, all students in the focus groups reported that the question and answer sequence resulted in more active involvement in learning when compared with traditional lecture-based classes. This was also confirmed by the survey [T2:S3]. The following is a typical student comment: 
With 100 people in the class [traditional] you normally just sit there without being involved . . . and add to your notes. In the NATALIE class everybody's involved, you have to think about what's being said . . you have to stay awake . . but it's more fun, you get more from it . . . better than just sitting taking notes.

Not only did students report that they were more actively engaged in learning but they also noted that they had more time 'to stand back' and reflect on concepts in a way that was not possible in most other lecture classes [T2:S4]. The opportunity to reflect was again seen to be a direct result of the structure of the sessions where there was a break after the presentation of material to think about the concept question alone or to discuss it in peer groups.

You have more time to think in that class because, it's structured, it's broken up. In a standard lecture it's difficult to spend time understanding the concepts ... you've got to keep up with the lecture . . . going ten to the dozen . . . and take notes. I mean in an ordinary lecture you might get through a lot of work but you won't understand what's going on.

According to the survey data the students' increased understanding was not perceived to be at the cost of more time spent studying outside class [T2:S5]. It is also notable that, in the focus groups, many students reported that their memory for material was better after a PRS class than after other classes. This was consistent with the survey data [T2:S6]

\section{Interaction and discussion}

In the focus groups, all students were convinced that discussion with other students in their peer groups played a central role in enhancing their understanding of concepts and ideas [T3:S1]. They maintained that peer discussion provided opportunities to think about the

\begin{tabular}{|c|c|c|c|}
\hline Number & Survey statement & $\begin{array}{l}\text { Students } \\
\text { agree } \\
(\%)\end{array}$ & $\begin{array}{l}\text { Students } \\
\text { diasagree } \\
(\%)\end{array}$ \\
\hline 1. & $\begin{array}{l}\text { Discussing PRS questions with other students in the class helps me } \\
\text { to understand better the subject matter }\end{array}$ & 92 & 0 \\
\hline 2. & $\begin{array}{l}\text { Hearing other students explain problems in their own words when } \\
\text { working in our small groups helps me to learn }\end{array}$ & 82 & 4 \\
\hline 3. & $\begin{array}{l}\text { A class discussion using the microphone is an important aspect of the } \\
\text { PRS class }\end{array}$ & 40 & 26 \\
\hline 4. & $\begin{array}{l}\text { I pay more attention in class when I know I might have to answer questions } \\
\text { with the microphone }\end{array}$ & 52 & 15 \\
\hline $\begin{array}{l}5 . \\
6 .\end{array}$ & $\begin{array}{l}\text { Hearing other students' explanations by microphone often confuses me } \\
\text { It is important that the teacher clearly explains which is the right answer } \\
\text { and why after a class discussion using the microphone }\end{array}$ & 37 & 31 \\
\hline
\end{tabular}

Note: See comment under Table 2.

Table 3: Student responses to end of semester survey 
problem in more detail, to explore alternative viewpoints and problem-solving approaches and to ask for, hear and try to reconcile different explanations. In effect, peer discussion helps students to elaborate and build upon their own personal framework of understanding. This finding is consistent with research from the United States (Dufresne et al., 1996; Crouch and Mazur, 2001).

A significant number of students in the focus groups also talked about the value of peer discussion by referring to a form of 'scaffolding' by fellow learners (see Bruner, 1985).

I think you can learn a lot easier from the people that are the same age as you ... if they've just grasped it then they can explain it in sort of easier terms than the lecturer ... you suddenly understand it when a minute before it was difficult

The language used by other students was seen as a critical component in fostering this new insight and understanding [T3: S2].

It's a language that you can understand between two students . . . whereas if its put forward by the professor he knows the deep meaning behind everything - he might make it more complicated than it needs to be.

In the focus groups, students expressed mixed views regarding their experience of classwide discussion and this was reflected in the survey where there was a mixed reaction to the statement 'a class discussion using the microphone is an important aspect of the PRS class' [T3:S3]. On the positive side, many students said that hearing other explanations - for correct and incorrect answers - from those outside their own group helped them grasp difficult concepts.

You are learning from people round you ... maybe someone at the other side of the room that understands a lot better than you, or the members of your group, and that [person] starts explaining it.

Also, over half the students reported that knowing that one might be called upon to explain the thinking behind a response encouraged them to formulate explanations in advance and that this increased attention levels during the class [T3:S4].

Despite these benefits, there were drawbacks to class-wide discussion. Some students reported that class-wide discussion took up too much time and that it was easy to drift away from the question or get confused about the answers [T3:S5].

The answers to the problems can sometimes get lost during class discussion particularly when there are a number of potential answers being discussed. If the discussion goes on for too long then interest can diminish it can also lead to confusion ... . it is easy to lose track of the main arguments.

The main recommendation made by students with regard to class-wide discussion and unanimously confirmed by the survey was that "the tutor clearly explains which is the right answer and why after a class discussion using the microphone' [T3:S6]:

It is important to get the final answer after having your own understanding and given your own, answer and had the class discussion ... you've thought about it in so many different ways and you've heard the logic of different answers . . . but which one is right? 


\section{Student motivation}

Discussing concept questions in class not only enhanced conceptual understanding but it also proved to be a powerful motivating force. In Week 5 students were asked (critical incident question): At what moment in the class did you feel most engaged with what was happening? Why? Over 90 per cent of the 100 students in class that day wrote that they were most engaged when they were interacting and discussing problems with other students and teachers.

Students also reported enhanced engagement when they received histogram feedback. Knowing that other students also gave wrong answers to concept tests had the effect of increasing their confidence [T4:S1] and their willingness to participate in peer and classwide discussions.

It helps you to learn to stand up for yourself and argue your point of view . . to be able to sit there and say that you are wrong is difficult for anybody but in there (the interactive classroom) it is easier because there are 50 per cent that were wrong as well, so it makes it easier. When you know that other people don't understand it, it makes you feel better ... in a lecture you wouldn't know that.

\begin{tabular}{|c|c|c|c|}
\hline Number & Survey statement & $\begin{array}{l}\text { Students } \\
\text { agree } \\
(\%)\end{array}$ & $\begin{array}{l}\text { Students } \\
\text { diasagree } \\
(\%)\end{array}$ \\
\hline 1. & $\begin{array}{l}\text { Seeing the class responses to a concept question (histogram) helps } \\
\text { increase my confidence. }\end{array}$ & 65 & 8 \\
\hline 2. & Using the PRS helps me pay attention in class. & 83 & I \\
\hline 3.' & $\begin{array}{l}\text { Using PRS (in mechanics) helps me enjoy this class more than traditional } \\
\text { lecture classes. }\end{array}$ & 98 & 0 \\
\hline $\begin{array}{l}4 . \\
5 .\end{array}$ & $\begin{array}{l}\text { The PRS approach should be used for other subjects. } \\
\text { Using PRS helps the teacher to become more aware of student difficulties } \\
\text { with the subject matter. }\end{array}$ & 76 & 2 \\
\hline
\end{tabular}

Note: See comment underTable 2.

Table 4: Student responses to end of semester survey

Some students also reported in the focus groups that it was reinforcing during the peer instruction sequence to see the class move from a situation where there was division about the correct answer (at first concept test) to a situation where the majority had correct responses (when retested).

When more of the class gets a correct answer the second time round you feel that you are making progress . . . that is, if your view has changed and you are now correct ... you know you have understood it better than before but also you feel that you are keeping pace with the class and that we're learning together

There was also consensus in the focus groups and survey that the varied structure of the teaching sessions with explanations, concept tests and discussion helped sustain students' attention in class [T4:S2].

Not only did most students experience these classes as 'involving' but over 25 per cent 
when asked (critical incident question) in Week 5, 'What most surprised you about this class?' wrote that they found the class enjoyable. This was confirmed by the survey [T4:S3] and by the fact that most students also thought that the PRS methods should be used in other classes [T4:S4].

Motivation and conceptual understanding are closely related in the experience of students. In the critical incident questionnaire students were asked: At what moment in the class did you feel most distanced from what was happening? Why? Over 50 per cent wrote that they felt most distanced when they did not understand something; for example, what other students were saying or the teacher's explanation of a concept. The survey data also show that students believed that the methods used in this class 'help the teacher become more aware of student difficulties with the subject matter' [T4:S5].

\section{Results: experiences of academic staff}

This section reports on the teachers' experiences in the interactive classroom.

\section{Conceptual understanding}

In the focus group with academic staff, there was also consensus that these new teaching methods were helping to improve the students' grasp of core engineering concepts. Two main reasons were given. First, the structure of PRS sessions around questions and answers provided benefits over conventional lectures; it made it possible for teachers to get immediate feedback about student difficulties and to reflect on the effectiveness of teaching while it was in progress. This feedback also made it possible to adjust teaching to the immediate needs of students.

The questioning process provides more feedback than traditional teaching methods. It gives you more information about where the students are coming from and you learn what misunderstandings or misconceptions they have and which ones can be easily straightened out.

Having time to observe is quite powerful. Even when you are on your own using PRS you have time to think - while students are discussing - about how things have gone and where you might go next with the teaching whereas in lecturing you are forced to keep the flow and there is little time to reflect. It can be difficult to think on the spot in a lecture class.

A second reason given for improved concept learning was related to changes in preparation. Instead of organizing a presentation, preparation now involved organizing short inputs around key concepts and the devising of concept questions. The construction of effective questions was considered central to the success of these teaching methods. Teaching staff talked about trying to identify 'what it is about the subject matter that makes it difficult for students' and about trying to formulate a concept question that would focus on this difficulty. Different types of questions had been used in class: questions where students had to order items; factual questions where they had to select the best definition; questions where they had to calculate something (for example, pressure under certain conditions) then select the answer; comparative questions (for example, if you input heat does the pressure go up, down or stay the same). One member of staff with more experience of PRS talked about categorizing question types according to Bloom's 
taxonomy (1956) and about sequencing questions so that there was a move to increasing levels of difficulty as the class progressed.

In order to create discussion amongst students, concept questions must produce a spread of responses. Teachers reported that if the pattern of correct responses was between 40 and 60 per cent this would normally provide a good trigger for discussion. Some teachers noted that it was sometimes difficult to produce an appropriate range of answers so that students could not merely select the correct answer through a process of elimination. Others noted that in some circumstances the thought processes required for logical elimination were themselves worth testing.

To date, the department has not analysed students' responses to questions from the logs that were available on the computer. The teachers agreed that these logs would provide useful information about the effectiveness of certain questions and that they could be used to develop a systematic database of areas of student difficulty with concepts. However, taking notes during class and keeping a teaching diary were seen as positive alternatives to $\log$ analysis because these processes encouraged reflection during teaching rather than much later.

While recognizing the value of these technology-supported discussion methods for concept learning, the focus group also helped clarify one potential limitation of these methods, namely, that they 'only tackle bites of knowledge but that the integration of lots of bites is also important' (see discussion section). Another issue discussed was whether teachers could 'cover as much material' in class using these methods. Most teachers maintained that teaching around concepts might either reduce or increase input but that this depended on how students responded to concept tests. From this perspective, these methods were seen as a more efficient way of teaching.

\section{Interaction and discussion}

There was consensus in the focus groups that peer discussion was central to these new teaching methods because of the way it engaged students actively in learning:

Students in this mode are reinforcing their own learning by actively reflecting on and articulating their own learning processes without them even knowing.

It was also agreed that peer discussion was an effective way of acclimatizing students to the specialized language of the discipline:

If you get questions and then peer discussion then students learn to use similar words to those the teacher uses to describe problems. The peer discussion also acts as a bridge enabling students to translate our words into their own words.

However, some members of the focus group noted that the more abstract the subject matter the more difficult it was for the students to engage in peer discussion:

In mathematics the concepts are so fundamental and there is a need to test each little bit but it is difficult to get meaningful discussion around very small bits

Others argued that problems in mathematics often revolve around considerations of the correct (mathematical) processes to be used and that the peer discussion could usefully focus on this. There is clearly scope for further research in such abstract disciplines. 
There were mixed views in the focus group about the value of class-wide discussion. It was noted that not everyone had the skills to manage large class discussions effectively and that it was time-consuming to implement.

When you do identify a spread of questions I feel I want to get into deeper dialogue through class discussion but class discussion takes up too much time.

Others remarked that if you ask for volunteers to contribute during class-wide discussion often the same students responded.

Despite these difficulties, most teachers reported that class-wide discussion had some advantages over peer discussion. In class-wide discussion, teachers can hear what the students think and this feedback is essential if they are to learn about areas of conceptual difficulty.

The focus group went on to identify a number of scenarios when it would be worthwhile using class-wide discussion despite the time considerations; (i) to find out why students got the wrong answer; (ii) to check students' interpretations of a question the first time you used it (for example, whether the wording was confusing); (iii) to find out what assumptions students were making in formulating answers.

\section{Student motivation}

All teachers maintained that these discussion methods are motivational in comparison with conventional lecturing. They talked about how using PRS raised the activity level in class, animated the students and kept them interested. It was also noted that attendance was always over 80 per cent in PRS classes and this was in spite of the fact that each class lasts two hours rather than the normal hour (total contact time was the same as other classes). In other lecture classes, the numbers normally drop off significantly as the semester progresses.

The teachers also believed that when students receive feedback information through the histogram display it has a motivational effect.

It gives students reassurance that they are not the only one who is wrong and makes the student feel more comfortable about admitting to his peers that she/he does not understand the concept

\section{Discussion}

In this final section we highlight some practical and research issues relevant to those who might wish to implement the interactive methods described in this paper.

The first issue is the added value provided by classroom communication technology. What does this technology provide over and above what could be achieved in more conventional class settings? The unique contribution of the technology is in the quality of feedback that it enables. Regardless of class size both teacher and students get almost instantaneous feedback about the distribution of student responses to a concept test in a situation where the respondents do not know what choices others are making. It would be extremely difficult to provide this kind of feedback in a large class by any other means (for example, a show of hands). In addition, students can quickly see how their personal response relates to the total distribution. This not only allows students to track their own progress in 
understanding relative to others in class but it also allows teachers to identify when students are encountering conceptual difficulties and to adapt their instruction in response. In many educational models, adaptive behaviour of this kind is seen as an essential component of good teaching (for example, Laurillard, 1993).

A second issue concerns the effectiveness of the different discussion methods. This evaluation has shown that classroom technology can support active discussion learning. However, it has also shown that peer discussion and class-wide discussion have different strengths. Peer discussion is superior to class-wide discussion if the goal is to increase the amount of interaction. The smaller numbers in the peer groups make it easier for all students to participate in discussion and students report that this method is less threatening than class-wide discussion. From this viewpoint, a key strength of peer discussion is that students are encouraged to construct and co-construct their understandings of core concepts in negotiation with others (Boyle and Nicol, 2003). In contrast, the main strength of class-wide discussion is that the teacher gains greater insight into why students misunderstand or misapply concepts. This is a result of the public nature of the discussion. This feedback is essential if teachers are to learn from their teaching and to teach more effectively in future (Laurillard, 1993). Yet, class-wide discussion is more difficult for teachers to manage, is more time-consuming and it can lead to student confusion. This comparison of the two discussion methods has not been researched until now despite its importance. At minimum, it suggests that teachers must think carefully about their reasons for implementing each discussion method. It also highlights the importance of pedagogical (and task) design when planning for the use of learning technologies (Mayes, 2001).

Other issues of concern are the integration of concepts and the time required to realign, teaching in relation to the discussion format. Teachers in this study felt that there was a danger that concept tests might result in student learning being overly focused on small 'bites' of information and that there was a need to test understanding not just of concepts but of their relationships. The idea that concept tests be planned as a sequence might go some way towards resolving this difficulty, as might the practice of constructing concept tests at different levels of granularity. Teachers also reported that test construction was not only time-consuming and complex but that it also involved trial and error learning in class to discover which concept tests were most effective. Hence, those new to these teaching methods will need to allocate time to build up a robust bank of effective test questions.

A final issue concerns the role of students in these discussion methods. It has been argued that these methods are student-centred in that they encourage active learning and reflection (Defresne et al., 1996). Yet both discussion sequences are normally triggered by questions formulated by teachers rather than by students. Therefore, it could equally be argued that these methods are, in some respects at least, teacher-driven. While this might be appropriate with first-year students there might be a need to shift the balance when dealing with students in their later years of study. One way to achieve this might be to involve students more actively in decisions about concept tests. Even using the PRS to ask questions such as 'do you want more on this topic?' during class, might help shift the balance in the students' direction. However, a more effective strategy would be to have students themselves (for example, in pairs) construct multiple-choice concept tests that could be used in class to challenge the learning of their peers. This strategy has been shown 
James T. Boyle and Dovid J. Nicol Using classroom communication systems in large class settings

to enhance understanding in other engineering contexts (see Panetta, Dornbush and Loomis, 2002).

\section{References}

Bligh, D. (2000), What's the Use of Lectures?, San Francisco: Jossey-Bass.

Bloom, D. (1956), Taxonomy of Educational Objectives, The Classification of Educational Goals - Handbook I: Cognitive Domain, New York: McKay.

Brookfield, S. D. (1995), Becoming a Critically Reflective Teacher, San Francisco: JosseyBass.

Brumby, M. N. (1984), 'Misconceptions about the concept of natural selection by medical biology students', Science Education, 68 (4), 493-503.

Bruner, J. (1985), 'Vygotsky: a historical and conceptual perspective', in J. V. Wertsch (ed.), Culture, Communication and Cognition, Cambridge: Cambridge University Press.

Cohen, E. G. (1994), 'Restructuring the classroom: conditions for productive small groups', Review of Educational Research, 64 (1), 3-35.

Comlekci, T., Boyle, J. T., King, W., Dempster, W., Lee, C. K., Hamilton, R. and Wheel, M. A. (1999), 'New approaches in mechanical engineering education at the University of Strathclyde in Scotland: I - Use of technology for interactive teaching', in G. Saglamer (ed.), Engineering Education in the Third Millennitum, Leuchtturm-Verlag.

Crouch, C. H. and Mazur, E. (2001), 'Peer instruction: ten years of experience and results', American Journal of Physics, 69, 970-7.

DeCorte, E. (1996), 'New perspectives on learning and teaching in higher education', in A. Burgen (ed.), Goals and Purposes of Higher Education, London: Jessica Kingsley.

Dufresne, R. J., Gerace, W. J., Leonard, W. J., Mestre, J. P. and Wenk, L. (1996), 'Classtalk: a classroom communication system for active learning', Journal of Computing in Higher Education, 7, 3-47.

Edwards, H., Smith, B. A. and Webb, G. (2001), Lecturing: Case Studies, Experience and Practice, London: Kogan Page.

Glaser, R. (1990), 'The re-emergence of learning theory within instructional research', American Pscyhologist, 45 (1), 29-39.

Hake, R. R. (1998), 'Interactive engagement versus traditional methods: a six-thousand student survey of mechanics test data for introductory physics courses', American Journal of Physics, 66, 64-74.

Halloun, I. A. and Hestenes, D. (1985), 'The initial knowledge state of college physics students', American Journal of Physics, 53, 1043-55.

Laurillard, D. (1993), Rethinking University Teaching, London: Routledge.

MacGregor, J., Cooper, J. L., Smith, K. A. and Robinson, P. (2000), Strategies for Energizing Large Classes: From Small Groups to Learning Communities, San Francisco: Jossey-Bass. 
Matthews, R. S. (1996), 'Collaborative learning: creating knowledge with students', in M. Menges, M. Weimer and associates (eds), Teaching on Solid Ground, San Francisco: JosseyBass,

Mayes, T. (2001), 'Learning technology and learning relationships', in J. Stephenson (ed.), Teaching and Learning Online, London: Kogan Page.

Mazur, E. (1997), Peer Instruction: A User's Manual, New Jersey: Prentice Hall.

McDermott, L. C. (1984), 'Research on conceptual understanding in mechanics', Physics Today, 37 (7), 24-32.

Nicol, D. J. and Boyle, J. T. (1993), 'Peer instruction versus class-wide discussion: a comparison of two interaction methods in the wired classroom', Studies in Higher Education, 28 (4), 457-73.

Palinscar, A. S. (1998), 'Social constructivist perspectives on teaching and learning', Annual Review of Psychology, 49, 345-75.

Panetta, K. D., Dornbush, C. and Loomis, C. (2002), 'A collaborative learning methodology for enhanced comprehension using TEAMThink', Journal of Engineering Education, 223-9.

Springer, L., Stanne, M. E. and Donovon, S. (1999), 'Effects of small group learning on undergraduates in science, mathematics, engineering and technology: a meta-analysis', Review of Educational Research, 69 (1), 50-80.

West, L. H. T. and Pines, A. L. (1985), Cognitive Structure and Conceptual Change, New York: Academic Press. 